Western University

Scholarship@Western

Education Publications

Education Faculty

6-4-2014

\title{
Using Mand Training to Increase Vocalization Rates in Infants
}

Gabrielle Lee

Western University, glee329@uwo.ca

Nicole Luke

Surrey Place Centre

Hye-Suk LeePark

Sam Houston State University

Follow this and additional works at: https://ir.lib.uwo.ca/edupub

Part of the Education Commons

Citation of this paper:

Lee, Gabrielle; Luke, Nicole; and LeePark, Hye-Suk, "Using Mand Training to Increase Vocalization Rates in Infants" (2014).

Education Publications. 143.

https://ir.lib.uwo.ca/edupub/143 
Running Head: USING MAND TRAINING

Using Mand Training to Increase Vocalization Rates in Infants

\author{
Gabrielle T. Lee ${ }^{\mathrm{a}}$, Nicole Luke ${ }^{\mathrm{b}}$, Hye-Suk LeePark ${ }^{\mathrm{c}}$ \\ ${ }^{\mathrm{a} A B A}$ Services \\ ${ }^{\mathrm{b} S u r r e y ~ P l a c e ~ C e n t r e ~}$ \\ ${ }^{\mathrm{c} S a m}$ Houston State University
}

Lee, G. T., Luke, N., \& LeePark, H. (2014). Using mand training to increase infant vocalizations. The Psychological Record, 64(3), 415-421. DOI 10.1007/s40732-014-0063-6 


\begin{abstract}
The present study examined the effects of a mand training procedure on the rates of vocalizations in two infants. Both typically developing girls were less than six months old at the onset of the study. An ABCBC reversal design was employed to compare the rates of vocalizations in baseline conditions, a mand-training condition, and a differential reinforcement for other (DRO) condition. A state of deprivation was held constant for both infants across all three conditions in which neither infant was fed for one hour prior to the experimental session. The order of conditions was reversed for the second infant and sessions lasted no longer than three minutes one time per day. Findings suggested significant effects of the mand-training condition on increased rates of vocalizations for both infants. These results are discussed in terms of verbal behavior analysis, our assumptions about the developmental trajectory of the function of language, and the implications for early language intervention programs.
\end{abstract}

Key words: mand, verbal behavior, motivating operations, language development, early language intervention 


\section{Using Mand Training to Increase Vocalization Rates in Infants}

Skinner (1957) defined verbal behavior as behavior that is reinforced through the mediation of a listener. One verbal operant, called a mand, specifies the reinforcement and appears to occur under the functional control of a state of deprivation associated with that reinforcement. The mand, like other operants, is defined by its function, not by its form. Skinner (1957) suggested that even the earliest sounds made by an infant in certain states of deprivation can be conditioned as a verbal operant when a listener supplies the necessary reinforcement and a learning history accrues. Thus, functional analysis of verbal behavior suggests that, even early sounds, under the right conditions, can become mands (Bijou, 1993; McLaughlin, 2010; Novak \& Pelaez, 2004; Schlinger, 1995; Skinner, 1957). In addition to the theoretical assumption that mands may be the first acquired verbal behavior for human infants in the form of vocalizations, infant vocalizations are considered one of the most important foundational verbal skills and appear to be critically related to the development of language in subsequent stages (Novak \& Pelaez, 2004).

Researchers have investigated the role of reinforcement in early language acquisition and demonstrated that language acquisition in human infants is operant in nature (Moerk, 1986, 1990, 1992; Gewirtz \& Pelaez-Nogueras, 1992). Specifically, infant vocalizations have been increased through social stimulation (Ramey \& Ourth, 1971; Rheingold, Gewirtz, \& Ross, 1959; Todd \& Palmer, 1968; Poulson, 1983), contingent maternal vocal imitation (Pelaez, Virues-Ortega, \& Gewirtz, 2011), and contingent responding using short sentences with high-pitched voices (e.g. motherese) (Pelaez, Ortega, \& Gewirtz, 2011). Routh (1969) found that reinforcement targeting 
certain vocal sounds was functionally related to the increase of those sound productions in infants. Infants (ages 9 to 13 months) also learned to imitate specific vocal sounds from adults through modeling as the antecedents and social praises as the consequences (Poulson, Kymissis, Reeve, Andreatos, \& Reeve, 1991). Although these studies demonstrated the operant process of language acquisition in early years, the application of verbal behavior analysis to the function of infant vocalizations is omitted.

Two research studies identified the mand as the primary function of emergent verbal behavior (in the form of sign language) in infants (6 to 15 months) using a modified functional analysis method (Normand, Machado, Hustyi, \& Morley, 2011; Thompson, Cotnoir-Bichelman, McKerchar, Tate, \& Dancho, 2007). The researchers reported that their participants had no vocal language nor did they use gestural signs to communicate, but whether the participants emitted vocalizations or had an imitative repertoire prior to the sign language training was not reported.

Haughan and McIntire (1972) conducted a study that is potentially relevant to the acquisition of mands in early years. They compared the relative effectiveness of social consequences, tactile stimulation, and food, and found social consequences most effective in increasing vocalizations. In their discussion, Haughan and McIntire (1972) suggested that the superior effectiveness of the social consequences that they found in their study may have been the result of the antecedent conditions of deprivation for social consequences as the participants were institutionalized and may have been deprived of social contact. Given the unspecified arrangements of deprivation/ antecedent conditions and the arbitrary selection of food items as reinforcers, the results of their study are potentially confounded. In addition to this, their study used a between subject group comparison, where eight infants with various ages were assigned to one or the other type of reinforcement and the collective results of vocalization rates were 
compared between groups. Thus, the individual differences in response to each type of reinforcement are unknown. To clarify the function of infant vocalization, it is necessary to arrange relevant antecedent conditions with a specified consequence in the context of verbal behavior.

Laraway, Snycerski, Michael, and Poling (2003) refer to what they called "motivating operations" or "MOs." This term is defined as those stimuli or conditions in the environment that exist prior to the emission of a behavior and that function to alter the momentary effectiveness of another stimulus occurring as reinforcement after the emission of the behavior. Relevant MOs serve to occasion the occurrence of mands associated with them. A particular mand (water, please) is more likely to occur as a function of a particular $\mathrm{MO}$ (water deprivation), especially with the presence of relevant discriminative stimuli (a glass of water within eyesight). The relationship between the motivating operation and the antecedent conditions to which Skinner (1957) referred appear to be temporal in nature and both may be manipulated in some mand training procedures (Greer \& Ross, 2008; Sundberg \& Partington, 1998). Mand training procedures include arranging a state of deprivation. A target item may be withheld for a certain amount of time prior to mand training sessions (motivating operation) and then presented out of reach but within eyesight (antecedent conditions) of the individual learner. The instructor may then provide the learner with an echoic model (e.g. "cookie") and deliver the cookie if the individual learner emits the verbal response "cookie." Prototypical mand training from the verbal behavior model attends to both the antecedent condition and the delivery of the specified reinforcement. Mand training is recommended as an essential element of early language training programs for children with language delays (Greer \& Ross, 2007; Sundberg \& Partington, 1998; Sundberg \& Michael, 2001). This approach traditionally assumes that echoic behavior should be 
acquired before mand training, leading one to assume a particular order in the development of the function of language as researchers in early language development suggest is the case with the development of the form of language (e.g., Guess, Sailor, \& Baer, 1976). However, such an assumption is inconsistent with a theoretical analysis of verbal behavior which suggests mands as the first acquired verbal operant in human infants.

Drash, High, and Tudor (1999) found that teaching the mand operant induced sound production and facilitated the acquisition of echoic behavior in young children with autism and language delays. These findings suggest that perhaps the echoic or imitative repertoire in the development of the function of language is not as assumed in traditional language training programs or that there is no particular order in the development of some functions of language (e.g. mand and tact acquisition). However, Drash, High, and Tudor's research was conducted with young children with autism who were nonverbal and whether their findings can be replicated to typical infants is not clear.

The purpose of the present study is to demonstrate the early acquisition of mand operants by extending mand training to typically developing infants much younger than those identified in earlier research. The mand training procedure in the present study omitted the echoic modeling because of the youth of the participants. This study allows for further investigation into our understanding of the particular order in the development of the function of language from the perspective of verbal behavior and has the potential to expand our choices for early language training programs of children with language delays.

\section{Method}

\section{Participants}


Mimi and Anna served as participants in the study. Both were typically developing female infants. Both babies were selected primarily because they started to show an interest in table foods and their pediatricians suggested solid food as a supplement. Both babies were breastfed but were introduced to a small amount of baby food during their snack time once a day several days before the study began. The regular doctor well-baby check-ups revealed that both babies were within normal range of typical development at the time of participation in the study. Based on observations, both babies frequently used smiles, hand grabbing, eye contact, and occasional vocalizations when interacting with their caregivers and other adults. Both babies could make a variety of sounds but did not imitate vocal sounds made by others.

Mimi was four months and two weeks old at the beginning of the study and seven months old at the end of the study. She could turn her head towards sounds, visually track a moving object, and sometimes vocalized when people smiled at her. Mimi could manipulate, grasp and reach for a suspended ring, and bring the ring to her mouth. She could hold her head in midline position, push herself up on her forearms, sit with slight support for 10 seconds, and turn from back to side.

Anna was five months old in the beginning of the study and eight months old at the end of the study. Her hands and eyes were coordinated when reaching and picking up objects. Her eyes could follow a falling object. She would vocalize when someone played with her. She could turn from her back to her side, from her back to her stomach; she could use her whole hand to grasp a rod, cubes, and her own foot. She could sit alone without support for two seconds. Informed consent was obtained from the parents of the participants prior to the beginning of the study. 


\section{Setting}

The experiment was conducted in the infants' homes. During the experiment, a parent or caregiver stayed with the experimenter while the other members of the family, if present, were doing their daily activities in other rooms of the house. The infant was seated in a highchair facing the adults at the dining table. The solid food was selected and prepared based on the preference of each infant as reported by their caregivers. For Mimi, a cereal bowl with approximately two tablespoons of rice cereal mixed with water was placed on the dining table in front of her. For Anna, the arrangement was similar, except her food included baby cereal mixed either with pureed apples, sweet potatoes, or peaches. To ensure a state of food deprivation, the infants did not nurse nor were they given any solid food for at least one hour before each session.

\section{Experimental Design}

The study used an ABCBC reversal design (Cooper, Heron, \& Heward, 2007), consisting of an initial baseline during which infant vocalizations were ignored (i.e., no adult attention and food delivery), followed by a phase of mand training (contingent delivery of food for each instance of a vocalization), and then a differential reinforcement of other-than-vocalizations (DRO) phase as a control condition (Poulson, 1983; Poulson, 1984; Poulson \& Nunes, 1988). For Anna, an initial baseline condition was also implemented, but the order of mand training and DRO phases were reversed in order to counterbalance conditions (ACBCB reversal design). Each session lasted no longer than three minutes and a single session was conducted each day. During the experiment, if the infant fussed, whined, or cried for less than 10 consecutive seconds, the experimenter ignored the infant by turning her head away and resumed eye contact and smiling once the fussing, whining, or crying stopped. If the infant cried for more than 10 
consecutive seconds, the session was terminated. Only once during the study, for one infant, was a session terminated for this reason.

Baseline condition sessions were conducted during the afternoon snack time with at least one hour having elapsed since the baby had last eaten. The adults engaged in conversation with each other and looked and smiled at the infant but ignored any vocalizations. Food was present but not delivered for any reason.

Mand-training condition sessions were conducted during the afternoon snack time with at least one hour having elapsed since the baby had last eaten. The adults engaged in conversation with each other and looked and smiled at the infant. If the infant made a vocalization then a half baby spoon of cereal was delivered by the experimenter.

Differential reinforcement of other behavior (DRO) condition sessions were conducted during the afternoon snack time with at least one hour having elapsed since the baby had last eaten. The adults engaged in conversation with each other and looked and smiled at the infant. A timer was set for five seconds and food was delivered if the infant was silent during the five second interval. If the infant vocalized within the five second interval, the timer was immediately reset for another five seconds.

\section{Dependent Variable}

The dependent variable was the number of vocalizations per minute during experimental sessions. An instance of vocalization was defined as a discrete, vowel-like sound or consonantvowel sound (e.g., "ah," “eh," "huh," "heh," “dada," “dadada,”), emitted continuously for no more than three seconds and without pauses for more than one second, including babbling and cooing, but not accompanied by crying, whining, or fussing (Rheingold, Gewirtz, \& Ross, 1959). 
For example, if the infant emitted an "ah" sound, paused for one second, and emitted another "ah" sound, two instances of vocalizations were scored. If the infant emitted "dadada" continuously for more than three consecutive seconds, an instance of a vocalization was scored for the first three seconds, while another instance of vocalization was scored after three seconds for every three second period.

In this study, specific forms of vocalizations were not required or differentially shaped into specific mands. The vocalizations emitted by the infants were categorized as a response class of mands that is controlled by relevant antecedent arrangements, food deprivation as an MO, and food delivery as a consequence.

\section{Independent Variable}

The independent variable in this study included the use of a prototypical mand training procedure involving the confluence of multiple variables: the creation of a state of deprivation, the antecedent condition of the presence of the food, and the delivery of a specific reinforcement related to the condition of deprivation and the antecedent stimuli. Convergent multiple control was established at the onset of each session (Michael, Palmer, \& Sundberg, 2011; Skinner, 1957). Social reinforcement in the form of eye contact and smiling was provided continuously across all conditions: baseline, mand training, and DRO.

\section{Data Collection}

Frequency of vocalizations was recorded by the experimenter with a mechanical counter. The frequency of vocalizations during each three minute session was converted to rate- the number of vocalizations per minute in Figure 1. 
During the experiment, each instance of food delivery and consumption took two to three seconds. Vocalizations occurring immediately before or during the delivery and consumption of food were not counted.

\section{Interobserver Agreement}

Interobserver agreement was calculated for $36 \%$ of all sessions for both participants. An adult who was naïve to the purpose of the study was instructed to record instances of vocalizations using a mechanical counter from video tapings or direct observation, independently and separately of the experimenter. The percentage of agreement was calculated using the smaller number divided by the larger number and multiplied by 100 (Cooper, Heron, \& Heward, 2007). Agreement ranged from $87 \%$ to $100 \%$ with a mean of $99.6 \%$.

\section{Data Analysis}

In addition to visual analysis using graphical representations, Percentage of Nonoverlapping Data (PND), Percentage Exceeding Median (PEM), and Cohen's d were used to analyze the strength of association between interventions and behavior changes across experimental phases. PND indicates non-overlap between baseline and successive intervention phases. It was calculated by dividing the number of non-baseline points that exceeded the highest baseline points by the total number of non-baseline points and multiplying that number by 100 (Campell, 2004; Scruggs \& Mastropieri, 2001). A PND score of less than 50 reflects unreliable treatment; a score from 50 to 70 reflects questionable effectiveness of the treatment; a score from 70 to 90 reflects a fairly effective treatment; and a PND score larger than 90 indicates a highly effective treatment (Scruggs \& Mastropieri, 2010). Visual displays of the data for both of the infants showed high variability with outliers. Considering that PND statistics are overly sensitive 
to outliers and trend (Campell, 2004), PEM was also used. PEM was calculated by dividing the number of non-baseline points that exceeded the median baseline points by the total number of non-baseline points and multiplying that number by 100 (Wendt, 2009). A PEM score of less than 70 suggests a questionable or not effective treatment; a PEM score of 70 to 90 suggests a moderately effective treatment; and a PEM score of greater than 90 suggests a highly effective treatment. Cohen's d scores were calculated for the difference between means of two compared phases divided by a standard deviation for the data. A Cohen's d score of 0.2-0.3 suggests a small effect, a score of 0.5 suggests a medium effect, and a score of greater than 0.8 suggests a large effect (Brossart, Parker, Olson, Mahadevan, 2006; Wendt, 2009).

The mean, range, and standard deviation of the number of vocalizations per minute under each condition were also calculated for both infants (Table 1).

\section{Results}

Figure 1 depicts the rates of vocalizations across all experimental conditions for Mimi and Anna. Both infants' vocalization rates were at similarly low levels during baseline and DRO conditions. The rates of vocalizations were ascending and increased to high levels under mandtraining conditions with both infants.

Table 1 summarizes the range, mean, and the Standard Deviation (SD) of the number of vocalizations per minute for both babies under all conditions. Table 2 displays PND, PEM, and Cohen's D between Baseline No Food, Mand Training, and DRO conditions for Mimi and Anna.

For Mimi, the data were ascending from low levels to high levels during both mandtraining conditions. The effect sizes for the difference in vocalization rates between baseline (10 
sessions) and the first mand-training conditions (10 sessions) ( $\mathrm{PND}=90, \mathrm{PEM}=100$, Cohen's $\mathrm{d}=2.976$ ), and baseline and the second mand-training conditions (7 sessions) ( $\mathrm{PND}=71.42$, PEM100, Cohen's d=1.73) were large and significant. Mimi's vocalization rates in the first DRO condition (10 sessions) following a mand-training condition were initially high but decreased significantly to low levels (Cohen's d=1.8) and showed a similar pattern of responding during the second DRO condition (10 sessions) following the second mand-training condition (Cohen's $d=1.15$ ). Both comparisons suggest a significant effect of the mand-training condition on the rate of vocalization.

Anna's rate of vocalization was low with variability during the baseline (10 sessions) and the rate remained low with no trend during the DRO condition (10 sessions) following the baseline condition ( $\mathrm{PND}=0, \mathrm{PEM}=0$, Cohen's $\mathrm{d}=0.73$ ). The rate of vocalization increased significantly during the first mand-training condition (13 sessions) (Cohen's d=1.6) following the first DRO condition. The rate of vocalization increased significantly with a similar ascending trend when the second mand-training condition (11 sessions) was introduced following the second DRO condition (10 sessions) (Cohen's d=2.0). Again, these comparisons suggest a significant effect of the treatment condition on the rate of vocalization.

In summary, the results from the visual display show a clear difference between mand training and baseline as well as DRO control conditions, suggesting a functional relationship exists between mand training and increased rates of vocalizations. The statistical analyses further support such a relation by indicating a strong and significant treatment effect when comparing data across conditions.

\section{Discussion}


The present study extends the literature on the pre-word language development of typical infants by demonstrating that mand training resulted in increased vocalizations in infants as young as four months old. The findings provide evidence that, for these infants, the mand was the first acquired verbal operant. Infant vocalizations in early months can be increased through the contingent delivery of food with relevant motivating conditions, independent of social consequences. Consistent with previous studies using social consequences to increase infant vocalizations, the results of the present study suggest that the occurrence of infant vocalization in early months could be operant in nature.

The results of this study also extend Drash et al's (1999) findings for young children with autism to typically developing infants and have potential implications to facilitate early language training for a rising number of infants or toddlers at risk or already diagnosed with autism or other developmental disabilities. Though the data were not presented, the experimenter probed the infants' echoic behavior before and during the experiment, and confirmed with their caregivers that echoic behavior was not observed for both infants during the time of the experiment. This study supports Drash et al (1999) in suggesting that mand training may be implemented as the first step before the establishment of echoic behavior. Or conversely, that echoic behavior may not be required to establish a mand operant for a language learner. However, it is necessary for future research to replicate this procedure with young infants at risk or with developmental disabilities. Similarly, the same procedure could also be extended to other forms of mand training, such as sign language; suggesting that generalized motor imitation may not necessarily be required as a prerequisite skill for successful learning of sign language as mands for young children or infants with developmental disabilities who are nonverbal. The procedures used in this study were selected as a way to contribute further to the examination into both the 
role of the complex antecedent conditions and the specific reinforcement associated with a verbal operant (Skinner, 1957).

When examining data across conditions, both infants' data indicate that the vocalization rates were at low levels in the baseline and DRO conditions, indicating that the DRO schedule effectively served as an experimental control procedure, similar to an extinction procedure where reinforcement for vocalizations was diminished over the condition (Thompson \& Iwata, 2005). Although the vocalization rates under DRO conditions were similar to baseline, the relatively high rates at the initial sessions and quick decreases to low levels in DRO indicated that the vocalizations were under extinction due to the elimination of reinforcement.

Some potential limitations to the current study exist. In this study vocalizations were immediately followed by food delivery. This procedure might alternately be interpreted as a vocalization-food pairing procedure (e.g., Carroll \& Klatt, 2008; Esch, Carr, \& Michael, 2005). The procedure may lend itself to the conditioning of automatic reinforcement which, in turn, may be responsible for increased vocalizations (Sundberg, Michael, Partington, \& Sundberg, 1996). Future research in this area is warranted. Additionally, while this study controlled the MOs (both social and food) across all conditions, future research could manipulate the relevant MOs to demonstrate additional kinds of experimental control. For examples, experimenters could explore the use of an abolishing operation condition or a satiation condition to further investigate the effects of the antecedent on the mand operant. The crying behavior, if any, and non-vocal behaviors, such as smiling, reaching, and body movements displayed by infants that indicating the effect of relevant motivating operations should also be systematically varied and measured.

In this study, the phase change criterion was based on stability under baseline and DRO conditions but not under the mand training conditions, where phase changes were made while the 
data were still ascending. The decision to change phases under mand training conditions was made based on ethical and practical reasons. Because the babies were given a fixed amount of food and the increased rates of food consumption under mand training carried a risk of choking, mand-training conditions were terminated as soon as an ascending trend was established. The ascending trend in mand-training phases suggests a strong effect of the mand training procedure on increased vocalizations. Another technical problem of this study is that the emission of vocalizations was sometimes too rapid to maintain a discrete and contingent delivery of food on a continuous reinforcement schedule. For example, when the infants acquired the mand function for vocalizations under the mand condition, they sometimes emitted more than one discrete vocalization before the delivery of food and during the consumption of food. These concurrent vocalizations that were not followed by food delivery were not counted in this experiment, and thus, the occurrences of vocalizations during mand training were inevitably underestimated, suggesting that the effect of the mand training may have been even more significant than this study could calculate.

The pre-word stage in language acquisition typically receives little attention from the researchers in linguistics and child development. Most of the time, infant vocalizations, such as cooing and babbling, are analyzed in terms of basic units of phonemes or sounds occurring at a certain age (Novak \& Pelaez, 2004). Cooing and babbling are considered simply sounds not "language" that convey meaning in a context. The results of this study call for reconsideration of such a viewpoint. From a functional perspective, infant vocalizations not only fit the definition of verbal behavior but this study demonstrated that very young infants participated as speakers in an interaction with a listener for the purpose of accessing a specific reinforcement - the very 
definition of a mand. These findings suggest that vocal utterances can function as verbal operants long before they acquire the formal properties of language. 


\section{References}

Brossart, D. F., Parker, R. I., Olson, E. A., \& Mahadevan, L. (2006). The relationship between visual analysis and five statistical analyses in a simple $\mathrm{AB}$ single-case research design. Behavior Modification, 30, 531-563.

Bijou, S. W. (1993). Behavior Analysis of child development. (rev. ed.). Reno, NV: Context Press.

Campbell, J. M. (2004). Statistical comparison of four effect sizes for single-subject designs. Behavior Modification, 28, 234-246.

Carroll, R. A., \& Klatt, K. P. (2008). Using stimulus-stimulus pairing and direct reinforcement to teach vocal verbal behavior to young children with autism. The Analysis of Verbal Behavior, 24, 135-146.

Cooper, J. O., Heron, T. E., \& Heward, W. L. (2007). Applied behavior analysis, $2^{\text {nd }}$. ed. New Jersey: Pearson Education, Inc.

Drash, P. W., High, R. L., \& Tudor, R. M. (1999). Using mand training to establish an echoic repertoire in young children with autism. The Analysis of Verbal Behavior, 16, 29-44.

Esch, B. E, Carr, J. E., \& Michael, J. (2005). Evaluating stimulus-stimulus pairing and direct reinforcement in the establishment of an echoic repertoire of children diagnosed with autism. The Analysis of Verbal Behavior,21, 43-58.

Gewirtz, J. L., \& Pelaez-Nogueras, M. (1992). B. F. Skinner's legacy in human infant behavior and development. American Psychologist, 47, 1411-1422. 
Greer, R. D., \& Ross, D. E. (2008). Verbal behavior analysis: Inducing and expanding complex communication in children with severe delays. Boston: Allyn \& Bacon.

Guess, D., Sailor, W. S., \& baer, D. M. (1976). A functional speech and language training program for the severely handicapped. Lawrence, KS: H \& H Enterprises.

Laraway, S., Snycerski, S., Michael, J., \& Poling, A. (2003). Motivating operations and some terms to describe them: Some further refinements. Journal of Applied Behavior Analysis, $36,407-414$.

Haugan, G., M., \& McIntire, R. W. (1972). Comparisons of vocal imitation, tactile stimulation, and food as reinforcers for infant vocalizations. Developmental Psychology, 6(2), 201-209.

McLaughlin, S. F. (2010). Verbal behavior by B. F. Skinner: Contributions to analyzing early language learning. The Journal of Speech-Language Pathology and Applied Behavior Analysis, 5, 114-131.

Michael, J., Palmer, D. C., \& Sundberg, M. L. (2011). The multiple control of verbal behavior. The Analysis of Verbal Behavior, 27, 3-22.

Moerk, E. L. (1986). Environmental factors in early language acquisition. In G. J. Whitehurst (Ed.), Annals of child development (Vol. 3, pp. 191-235). Greenwich, CT: JAI Press.

Moerk, E. L. (1990). Three-term contingency patterns in mother-child verbal interactions during first-language acquisition. Journal of the Experimental Analysis of Behavior, 54, 293-305.

Moerk, E. L. (1992). First language: Taught and learned. Baltimore, MD: Brookes.

Novak, G., \& Pelaez, M. (2004). Child and adolescent development. Thousand Oaks, CA: Sage. 
Normand, M. P., Machado, M. A., Hustyi, K. M., \& Morley, A. J. (2011). Infant sign training and functional analysis. Journal of Applied Behavior Analysis, 44, 305-314.

Parker, R. I., Hagan-Burke, S., \& Vannest, K. (2007). Percentage of all non-overlapping data (PAND) : An alternative to PND. The Journal of Special Education, 40, 194-204.

Pelaez, M., Ortega, J., \& Gewirtz, J. L. (2011). Contingent and noncontingent reinforcement with maternal vocal imitation and motherese speech: Effects on infant vocalizations. European Journal of Behavior Analysis, 12, 277-287.

Pelaez, M., Virues-Ortega, J., \& Gewirtz, J. L. (2011). Reinforcement of infant vocalizations through contingent vocal imitation. Journal of Applied Behavior Analysis, 44, 33-40.

Pelaez, M., Vireus-Ortega, J., \& Gewirts, J. L. (2012). Acquisition of social referencing via discrimination training in infants. Journal of Applied Behavior Analysis, 45, 23-36.

Poulson, C. L. (1983). Differential reinforcement of other-than-vocalization as a control procedure in the conditioning of infant vocalization rate. Journal of Experimental Child Psychology, 36, 471-489.

Poulson, C. L. (1984). Operant theory and methodology in infant vocal conditioning. Journal of Experimental Child Psychology, 38, 103-113.

Poulson, C. L., Kymissis, E., Reeve, K. F., Andreatos, M., \& Reeve, L. (1991). Generalized vocal imitation in infants. Journal of Experimental Child Psychology, 51 (2), 267-279.

Poulson, C. L., \& Nunes, L. R. P. (1988). The infant vocal-conditioning literature: A theoretical and methodological critique. Journal of Experimental Child Psychology, 46, 438-450. 
Ramey, C. T., \& Ourth, L. L. (1971). Delayed reinforcement and vocalization rates of infants. Child Development, 42, 291-297.

Rheingold, H. L., Gewirtz, J. L., \& Ross, H. W. (1959). Social conditioning of vocalizations in the infant. Journal of Comparative and Physiological Psychology, 52, 68-73.

Routh, D. K. (1969). Conditioning of vocal response differentiation in infants. Developmental Psychology, 1, 219-226.

Schlinger, H. D. (1995). A behavior analytic view of child development. New York: Plenum Press.

Scruggs, T. E., \& Mastropieri, M. A. (2010). How to summarize single-participant research: Ideas and applications. Exceptionality: A Special Education Journal, 9, 227-224,

Skinner, B. F. (1957). Verbal behavior. New York: Appleton-Century-Crofts.

Sundberg, M. L., \& Michael, J. (2001). The benefits of Skinner's analysis of verbal behavior for children with autism. Behavior Modification, 25, 698-724.

Sundberg, M. L., Michael, J., Partington, J. W., \& Sundberg, C. A. (1996). The role of automatic reinforcement in early language acquisition. The Analysis of Verbal Behavior, 13, 21-37.

Sundberg, M. L., \& Partington, J. W. (1998). Teaching language to children with autism or other developmental disabilities. Pleasant Hill, CA: Behavior Analysts, Inc.

Thompson, R. H., Cotnoir-Bichelman, N. M., McKercher, P. M., Tate, T. L., \& Dancho, K. A. (2007). Enhancing early communication through infant sign training. Journal of Applied Behavior Analysis, 40, 15-23. 
Thompson, R. H., \& Iwata, B. A. (2005). A review of reinforcement control procedures. Journal of Applied Behavior Analysis, 38, 257-278.

Todd, G. A., \& Palmer, B. (1968). Social reinforcement on infant babbling. Child Development, 39, 591-596.

Wendt, O. (2009, May). Calculating effect sizes for single-subject experimental designs: An overview and comparison. Paper presented in The Ninth Annual Campbell Collaboration Colloquium, Oslo Norway. 


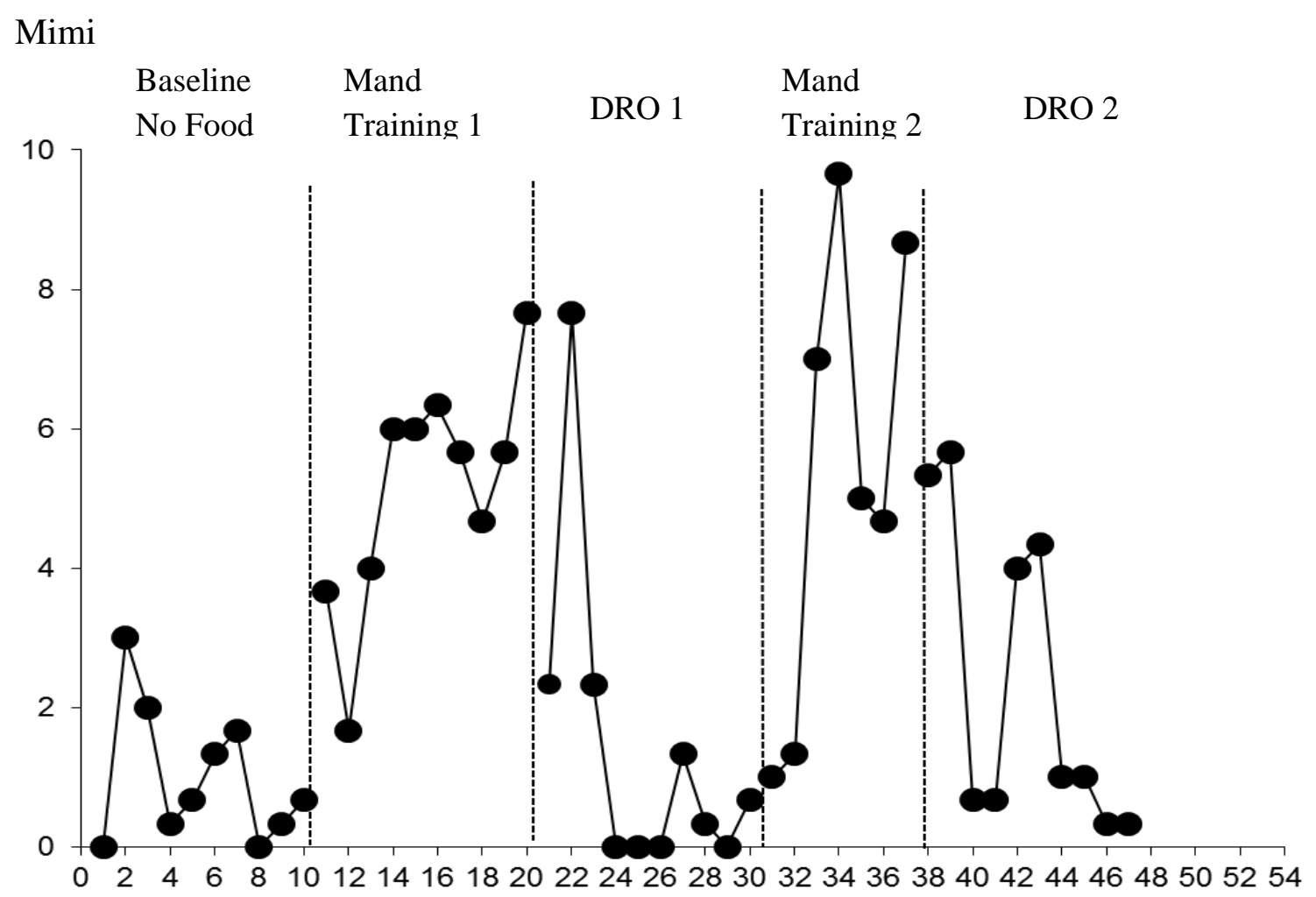

Anna

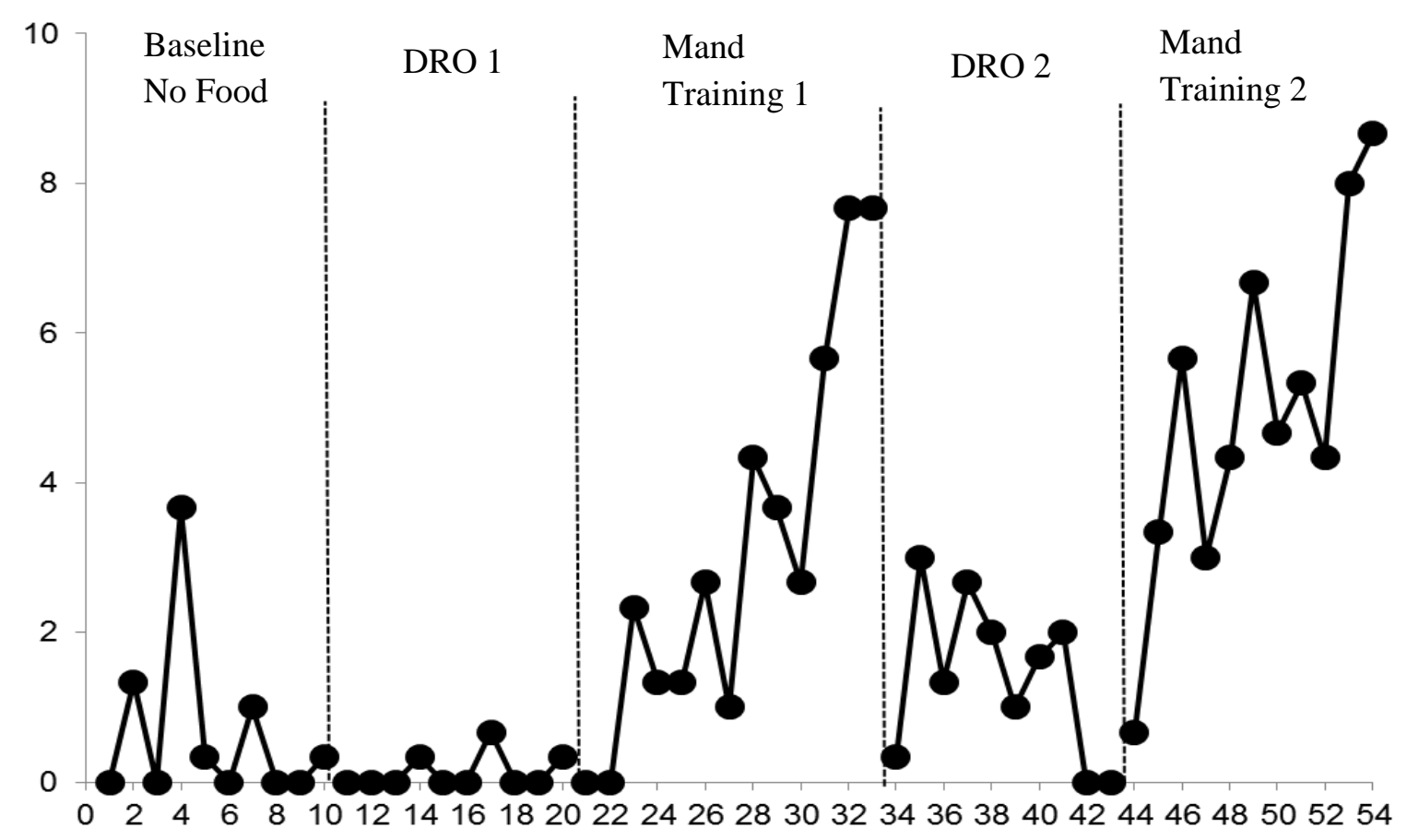

Figure 1. The rates of vocalizations across all experimental conditions for Mimi and Anna 
Table 1

Mean (Range) number of vocalizations per minute, and Standard Deviation (SD) under Baseline No Food, Mand Training, and DRO conditions for Mimi and Anna.

\begin{tabular}{|l|l|l|l|l|l|}
\hline \multirow{2}{*}{ Condition } & Baseline & Mand 1 & DRO1 & Mand 2 & DRO2 \\
\cline { 2 - 6 } Baby & M(Range) & M (Range) & M Range) & M (Range) & M (Range) \\
& SD & SD & SD & SD & SD \\
\hline Mimi & $1.0(0-3.0)$ & $5.13(1.7-7.7)$ & $1.46(0-7.7)$ & $5.33(1.0-9.7)$ & $2.33(0.3-5.7)$ \\
& 0.98 & 1.68 & 2.33 & 3.36 & 2.21 \\
\hline Anna & $0.67(0-3.7)$ & $3.10(0-7.7)$ & $0.13(0-0.7)$ & $4.96(0.7-8.7)$ & $1.40(0-3.0)$ \\
& 1.0 & 0.23 & 2.59 & 1.06 & 2.28 \\
\hline
\end{tabular}


Table 2

PND, PEM, and Cohen's D between Baseline No Food, Mand Training, and DRO conditions for Mimi and Anna.

\begin{tabular}{|l|l|l|l|l|l|l|l|}
\hline & & A-B & A-C & B-C & A-B' & A-C' & B'-C' \\
\hline \multirow{2}{*}{ PND } & Mimi & 90 & 10 & $*$ & 71.42 & 30 & $*$ \\
\cline { 2 - 8 } & Anna & 30.7 & 0 & $*$ & 80 & 30 & $*$ \\
\hline \multirow{2}{*}{ PEM } & Mimi & 100 & 41.6 & $*$ & 100 & 20 & $*$ \\
\cline { 2 - 8 } & Anna & 84.6 & 0 & $*$ & 100 & 90 & $*$ \\
\hline \multirow{2}{*}{ Cohen's D } & Mimi & 2.976 & 0.24 & 1.8 & 1.73 & 0.46 & 1.05 \\
\cline { 2 - 8 } & Anna & 1.17 & 0.73 & 1.6 & 2.43 & 0.7 & 2.0 \\
\hline
\end{tabular}

Note. $\mathrm{A}=$ baseline, $\mathrm{B}=$ Mand Training 1, $\mathrm{C}=\mathrm{DRO} 1, \mathrm{~B}$ '=Mand Training 2, C'=DRO 2, *=Not Available 